\title{
Children's Emotions in Educational Settings: Teacher Perceptions from Australia, China, Finland, Japan and Spain
}

\author{
Henna Pirskanen ${ }^{1} \cdot$ Kimmo Jokinen $^{1} \cdot$ Anu Karhinen-Soppi ${ }^{1} \cdot$ Marianne Notko $^{2} \cdot$ Tiina Lämsä $^{1} \cdot$ Midori Otani $^{3}$. \\ Gerardo Meil $^{4}$ - Pedro Romero-Balsas ${ }^{4}$ • Jesús Rogero-García ${ }^{4}$
}

Published online: 5 April 2019

(c) The Author(s) 2019

\begin{abstract}
The transition to formal education is a critical transition in children's lives that has importance for socio-emotional and behavioral functioning. In the transition process, teachers are key players who work intensively with children and their families. This article focuses on teachers' perceptions of children's socio-emotional behavior during the transition from preschool to primary school. We collected qualitative teacher interviews from 112 teachers from five different countries-Australia, China, Finland, Japan and Spain. The research questions were: (1) How do teachers in the five countries perceive children's abilities in expressing and regulating emotions. (2) How are children's emotions linked to their family relationships? (3) What similarities and differences across countries exist in teachers' perceptions of children's emotions? Overall, the interviewed teachers considered children's emotional skills of crucial importance in the first grade and emphasized the importance of teaching children emotional skills, emotion management and regulation. The teachers reported that children can be stressed, worried or anxious during the transition. The educators also reported that transitions in the family such as parental divorce, the birth of a sibling or the death of a family member can manifest in children at school as restlessness, excitement, sadness or instability. Similarities and differences in the emphasis placed on children's emotions by teachers were found across the five countries. We interpret these results to reflect differences in teacher education, school culture, resources and teachers' freedom of choice in the educational system in the different participating countries. These factors all impact on how teachers think about children and emotions.
\end{abstract}

Keywords Children · Transitions · Emotions · Teachers' perceptions · Families

\section{Introduction}

Contemporary families in the industrialized world are facing a growing number of transitions and greater diversity and complexity in the life paths of family members. Besides unexpected and unforeseen transitions, such as divorce or the

Henna Pirskanen

henna.pirskanen@jyu.fi

1 Department of Psychology, Family Research Centre, University of Jyväskylä, Mattilanniemi 6-8, 40014 Jyväskylä, Finland

2 Department of Social Sciences and Philosophy, University of Jyväskylä, Jyväskylä, Finland

3 Graduate School of Education, Shimane University, Matsue, Japan

4 Department of Sociology, Autonomous University of Madrid, Madrid, Spain serious illness of a family member, families encounter several expected transitions, such as when a child starts school (Jokinen and Kuronen 2011). The transition to primary school is a critical transition in children's lives. This phase of life marks a significant change in children's everyday actions and social relations and can be challenging for both children, parents and teachers. Thus, positive school entry is a significant step for children, whose socio-emotional and behavioral functioning is especially important in this phase of life (Pianta and Kraft-Sayre 2003; McIntyre et al. 2006; see Dockett and Perry 2015). Hence, in this article we concentrate on teachers' perceptions of children's emotions during the transition to first grade in school.

There is growing recognition of the importance of these early experiences in general (Ahtola et al. 2015; Balham et al. 2016; Corsaro and Molinari 2000, 2008; McIntyre et al. 2006; Wildenger and McIntyre 2012) and this specific transition has been explored from different perspectives, 
such as children's readiness, adjustment, continuity and change (e.g. Balham et al. 2016; Iorio and Parnell 2015). However, it is acknowledged that the transition needs to be understood more fully (Corsaro and Molinari 2000, 2008; Rimm-Kaufman and Pianta 2000). Emotions during the transition to middle school (Irvin and Richardson 2002), from vocational school to work (Nurmi et al. 2002), and from secondary to postsecondary education (e.g. Pekrun et al. 2018), have been examined. However, younger children's emotions in the transition to school have received less scholarly interest, in particular interest from a sociological perspective. Children enter primary school with different backgrounds, temperaments, experiences and knowledge sets, while teaching methods, community formation and school cultures also vary between schools. Consequently, each child experiences the transition differently (Dockett and Perry 2007; Garðarsdóttir and Ólafsdóttir 2017) and their emotions may vary accordingly.

Child care professionals, family counsellors, psychologists, social workers and other experts play important roles in today's childhood, upbringing, and education (see Giddens 1991; Hacking 2002). Teachers are key players in the transition to school, as they work intensively with children and their families to enhance this process. It is for this reason that we are interested in how teachers perceive children's socio-emotional behavior during this specific transition. To gain as broad a picture as possible of children's emotions and the social worlds connected to them in the school context, we collected data from five different countriesFinland, Australia, Spain, Japan and China. We view questions about transitions as international issues despite crosscountry country differences related to the age of starting school, school systems, and school curricula (see Fabian and Dunlop 2002).

\section{Transitions and Emotions}

In this article, "transition" refers to the process of change experienced by children when they move from one setting to another, such as from pre-school to primary school, or from one class to another during the school day. The transition of present interest includes the length of time that it takes to make the change. In the case of the school transition this can, for example, mean the time span between any pre-entry visit up to the point when the children have established themselves fully as members of the new educational setting. For a child, this is a period characterized by intense and socially regulated demands (Fabian and Dunlop 2002).

In the transition context, we understand emotions sociologically. Emotions are always shaped, named, evaluated and interpreted in a given social and cultural context. Emotional experiences have an interactive, relational character.
Emotions are also essentially bodily in nature, as they can be felt and expressed in the body (e.g. Smart 2011; Lupton 1998; May 2013). In school settings, students experience diverse emotions (Pekrun et al. 2018). In the case of the transition to primary school, the emotions that children experience are affected by their social context, i.e., the everyday life settings and important people that surround them. The school environment and curriculum as well as the children's families, educators, and peer relationships are examples of these settings and persons (see Margetts 2002). The transition to school means a re-organization of their roles for both the children and their parents, experiences that can be marked by strong emotions and even disharmony (Fabian and Dunlop 2002). These emotions may include excited anticipation, curiosity, and pride, but also stress, insecurity and fear (e.g. Niesel and Griebel 2005).

The concepts emotion work and emotion management proposed by Arlie Hochschild (e.g. 2005) are applied here to highlight different emotional skills and how individuals shape and reshape their emotions to fit cultural guidelines. People have several strategies for managing their emotions. These can be drawn on consciously or unconsciously, but emotion management often requires identifying one's emotions first if one is to work on them. In the case of children entering primary school, emotion management requires identifying and working on the emotions evoked by their new social context.

Emotional competence is another concept used in the context of early education. Emotional competence consists of emotion knowledge, i.e., the ability to discern other people's emotions from contextual and expressive cues, emotion regulation, i.e., the ability to modify one's own emotional states, and emotion expression in social situations (Miller et al. 2006; Denham et al. 2003; see Pekrun et al. 2018). An array of studies has investigated children's emotional competence in preschool and its interrelations with adjustment (e.g. Miller et al. 2006) and social competence (e.g. Denham et al. 2003), and as a predictor of behavior in the later school years (e.g., Fine et al. 2003).

Whether we use the term emotion work, emotion management or emotional competence, we are referring to the processes through which children learn how to work on their emotions and the social relationships connected to them. Here, our interest is in children's ways of expressing their emotions in the school context as perceived by teachers. Teacher education and its contents have significant effects on the meanings teachers attribute to children's behavior. Teachers' perceptions of children's emotions are also closely connected to how they define good or bad behaviour, or a competent student, and to the norms prevalent in the broader societal and cultural context (see Lanas and Huuki 2017; Koskela and Lanas 2016; Manninen et al. 2011). 


\section{Data and Analysis}

In a multidisciplinary research project 'Dalfa (Daily life in transitions, children in multiple family forms, 2015-2019)', both quantitative and qualitative data on the transition from pre-school to primary school were collected from both children and first-grade teachers. In this article, we focus on qualitative interview data collected from teachers in five countries. We interviewed a total of 112 teachers, using both individual and group interviews, in Australia $(\mathrm{N}=16)$, China $(\mathrm{N}=10)$, Finland $(\mathrm{N}=33)$, Japan $(\mathrm{N}=26)$ and Spain $(\mathrm{N}=27)$. In each country, teachers were interviewed in their native tongue or in English, according to the participant's wishes. Interviews were conducted in both urban and semi-rural areas. The teachers' interviews focused on four themes: (1) the social worlds of the children at school and at home, (2) transitions in children's lives at school and at home, (3) the emotions and everyday life of children at school, and (4) the transition from home care or pre-school/kindergarten to school. Both the group and individual interviews, although slightly different in their dynamics of interaction, yielded similar responses from the teachers. The interviews were recorded with a digital recorder and transcribed, and those conducted in a language other than English were translated into English. All the interviews were anonymized and pseudonymized.

In cases where research permits were needed to conduct the interviews, they were granted by the municipality and/or school. Teachers were asked for their written informed consent. The purpose and the voluntary nature of the study, participants' right to withdraw at any point during the research process, and data protection and anonymization were carefully explained. We have followed the principles of remaining alert and ethically sensitive and reflecting on the consequences of all our actions throughout the research project (Notko et al. 2013). The research plan has been approved by the ethics committee of the University of Jyväskylä.

The research questions addressed in this article were: (1) How do teachers in the five countries perceive children's abilities in expressing and regulating emotions. (2) How are children's emotions linked to their family relationships? (3) What similarities and differences across countries exist in teachers' perceptions of children's emotions? The aim was to highlight the diversity and multiplicity of experiences and strengths in different countries.

Data were analyzed using thematic and content analyses. First, the transcripts were carefully read and coded by three researchers into preliminary themes, and tables illustrating these themes in each country were constructed. Next, the themes were further elaborated by deducing them into two groups to gain a more thorough grasp of, first, teachers' perceptions of children's skills in the expression and regulation of emotions and, second, the role of the family in first-graders' emotions. The data were then further coded into subthemes and analyzed to investigate similarities and differences between the five countries. A table illustrating these similarities and differences was then constructed. While not all the teachers in the same country shared the same perceptions we highlighted the dominant ideas of the teachers in each country. For example, although not every teacher interviewed in Finland accentuated the importance of children's emotional skills, this was nevertheless a dominant theme across the Finnish interview data.

\section{Educational Systems of the Five Participating Countries}

While an institution for pre-primary education exists in all five countries, they vary in their definitions of early childhood and primary education, as well as in their educational systems. In addition, some children may not attend early childhood education or pre-school at all, but rather enter school directly from home care. Here, we define "preschool" as the year preceding the start of formal education in primary school. The enrolment age for primary school also varies from 5 to 7 years across the countries. In Australia, Finland, Japan and Spain, the enrolment rates for preschool education were more than $90 \%$ in each country in 2014 (OECD 2017). In China, statistics are available for the enrolment rates for pre-school children aged 3-6 years. The rate has grown rapidly during recent years and was $86 \%$ in 2017, compared to 50\% in 2009 (UNESCO 2019). On the other hand, enrolment rates at age three vary from around $70 \%$ in Australia and Finland, to around $80 \%$ in Japan, and to more than $90 \%$ in Spain (OECD 2017). In each country, the interviewees showed awareness of the importance of the transition to compulsory education for young children (e.g. Hännikäinen 2003; Xu 2011). Although for reasons of space we cannot describe in detail the educational systems, teacher training programs and school cultures in each country, we offer the following outline of their respective school systems.

In Australia, the preschool program is available for all children in the year before full-time school (Department of Education and Training 2018). Compulsory school starts at the age of 5 or 6 years depending on the state and territory. States and territories are responsible for school education (Australian Government 2019). The education system is broadly structured as follows: Primary school lasts for seven or 8 years, starting at Foundation (also called kindergarten/preparatory/pre-school). Secondary school lasts for 4 years, and senior secondary school 2 years (Department of Foreign Affairs and Trade 2019).

In China, the public school system provides formal education for 12 years, 9 of which are compulsory. Three types of early education programs exist prior to entry to primary 
school at age 6. Although pre-school education is not compulsory, children are offered a minimum pre-primary program lasting 1 year (OECD 2016; Xu 2011). Education has traditionally been valued and emphasized in China. Confucianism has occupied a significant role in the Chinese educational system (Xu 2011). The country has made a series of efforts aimed at promoting the development of early childhood education by introducing China's National Plan for Medium- and Long-term Education Reform and Development (2010-2020) (China State Council 2010).

In Finland, children start their 9 years of compulsory comprehensive education at age 7. Since 2015, preschool education during the preceding year has also been compulsory and free of charge for every 6-year-old child (Basic Education Act 1998, 26 a §). Preschool education is based on play-like, developmentally appropriate activities. During the first years of primary education, readiness for later learning is developed through the acquisition of literacy, mathematical and social skills, among others (Hännikäinen 2003).

In Japan, compulsory comprehensive education starts at age 6 and lasts 9 years. Elementary schools aim at giving children between the ages of 6 and 12 a general primary education suited to their stages of mental and physical development. The first year is key for the development of both children's academic and social skills. Three types of pre-school institutions are offered: kindergarten, nursery school, and a center for early childhood education and care. Each of these comprehensively provides preschool children with a unified education and childcare, and their parents with childcare assistance (Ministry of Education, Culture, Sports, Science and Technology 2016).

In Spain, compulsory comprehensive education starts at age 6 and lasts 10 years. Although non-compulsory, children aged between 3 and 5 years have had the right to a free preschool education since 1990 (Education Act 1990). In 2015, 95\% of 3-year-old children were enrolled in preschools (Ministry of Education, Culture and Sports 2018). Regional governments define the main educational goals for the preschool period. The teaching methodology is usually based on creative and interactive play, although during the final stage children engage in more teacher-directed activities focused on the development of reading and writing skills (Alcrudo et al. 2015).

\section{Results}

\section{Children's Skills in the Expression and Regulation of Emotions in the First Grade}

Because children experience multiple emotions during the transition to formal education, the teachers emphasized the importance of emotional skills in the first grade. Teachers in all five countries understood emotional skills as comprising the ability to understand other children's emotions, show empathy and solve problems with friends. The teachers recognized that children differ in their levels of academic and socio-emotional skills at school entry. Hence the importance of children experiencing positive emotions, such as happiness and excitement, at the start of their first school year was a recurrent theme in the teacher data. In general, children were reported to express emotions openly towards other children and teachers and to show empathy towards others, even if they were not yet able to communicate their emotions verbally. At the beginning of elementary school, first-graders were considered to need closeness, hugs, and a caring environment, and the teachers saw themselves as key players in creating an atmosphere of this kind. The teachers also acknowledged that children may have negative emotions or exhibit problematic behavior during this phase.

FT10 ${ }^{1}$ : I feel that there is more and more of a need to handle emotions with children and think about different reactions, and our class received emotion and safety skills materials during this spring, and we have reviewed this on a weekly basis. There is a need for it. And we have practiced social situations via pantomime. Like if we had an argument now, how would you react and what would you do? And if you got angry, in what ways would you control anger? At least I feel I need to give it [the topic] space. [..] It's an increasingly visible part of work in educating and teaching.

The teachers underlined the importance of teaching children emotional skills and emotion management. At the start of school, socio-emotional skills were perceived as being more important than academic skills, since the possession of adequate social and emotional skills is a prerequisite for learning. The teachers trusted that the children would learn the academic skills required by the curriculum later, during the first grade. Some teachers, most notably in Australia, Finland and Spain, reported putting a lot of effort into teaching first-grade children to identify, express, and manage emotions.

AT10: It's group work as well as individual work, how to make that group. [...] And, you know, have circle times ${ }^{2}$ if it's not working, and working it out. And I think the other thing then is that we're

\footnotetext{
1 The first letter in the code refers to the country of the interview, and number to the running number of the teacher interviewed in each country. E.g. FT10 signifies Finnish teacher number 10.

${ }^{2}$ Circle time means time in the class during which children and teachers sit on the floor in a circle and communicate their experiences, emotions, problems and other issues.
} 
problem-solvers, we're all problem-solvers. We sit down and we talk about what's going on and how we could make it better. Are we all happy with it or not and how we can make it move forward. That's really authentic learning, that's where their life skills are being learnt, social and emotional.

ST14: When we work on emotions, in a more direct way, they learn to be aware and work with different techniques, related to relaxation, breathing exercises, as mentioned before: "Well, I'm angry, it's ok, I express it, I release it. [...] It's true that we consider that it's fundamental for them to know and identify what they are feeling.

The teachers had a multitude of techniques for enhancing children's emotional skills. Several teachers reported that they had participated in training on the theme. In addition, the teachers in Finland, Australia and Spain felt that it was their responsibility to teach socio-emotional skills and emotion management whenever situations occurred that demanded that they react. The teachers in all five countries felt that children also need to learn to recognize their negative emotions, among other things as a way of preventing violence towards other children, a theme that was brought up by the Japanese and Chinese teachers in particular.

JT 16: It's difficult for first graders to think of a way of expressing themselves to others so that they can be understood. That is a challenge for them. As a result, first graders have a tendency to take physical action instead. When they are happy, it is okay to express it with actions. We can share positive feelings with them easily. However, when they are going through negative feelings and expressing those by actions, they can cause bigger problems to others. Thus, I believe it is essential to teach first graders how to explain themselves with words little by little. They need to understand that they cannot use hitting or other violence to express their emotions on any occasion and the importance of explaining themselves to others.

In the Asian Confucian culture, the values of harmony, good behavior and maintaining order while keeping face, have traditionally been regarded as important. Hence, violence and the expression of negative emotions such as anger or sadness may be perceived to disturb this balance (Trommsdorff and Kornadt 2003), perhaps to a greater extent than in Western countries. Negative emotions among children were more rarely considered problematic by the teachers in Finland, Spain and Australia. In China, enhancing children's emotional skills was talked about in only one interview. Otherwise, the Chinese teachers stressed the changeable and uncontrollable nature of first graders' emotions.
The teachers recognized both that children have individual differences in their levels of emotional skills and that these are influenced by their family upbringing. If children are taught emotional skills at home, they benefit from these skills at school as well. The educators in Finland, Australia, Spain and Japan also reported that children develop these skills during the first grade.

FT18: This is an environment where different personalities and cultures meet, how emotions have been handled, and it is probably terribly important how emotions are [handled] at home and what kind of home environment there is.

In the educators' views, some children can be stressed, worried or anxious during the beginning of their first school year. This presents children in the transition phase with a challenge on the emotional level. The teachers saw stress as deriving from the pressures of academic performance, which affects anxious parents as well as children and teachers. Teachers in Japan, Spain and China raised this issue.

ST13: At the beginning of the school year, it's a bit hard for the kids. We follow the routines, but it's hard for them. Then, we get a bit overwhelmed. [...] It's a bit stressful, for all of us. Parents also get rather anxious, because they phone us. Parents also expect a lot from us, they want us to, they want their kids to achieve these objectives, and we talk with them, but there's a bit of stress at the beginning.

For example, having books and worksheets instead of play, long school days and the pressure of learning to read were some of the factors reported by teachers that could cause children to feel tired and stressed. The routines and everyday temporal, material, and social arrangements of the school day thus had an impact on children's emotional experiences at the beginning of elementary school.

\section{The Role of the Family in First-Graders' Transitions and Emotions}

One of our research interests is in the possible links between children's emotions during the transition to school and other transitions that simultaneously take place in the family. Some teachers reported that changes in the family, such as parental divorce or a birth of a sibling, may manifest in first-graders at school as restlessness, anger, sadness, instability or the inability to perform (see also Amato 2000, 2010; Heath and Cole 2012; Legg et al. 1974). The teachers also reported that positive family transitions may cause children to feel happy and excited. 
ST9: These changes are noticeable sometimes, because children might be more irritable. It's noticeable because you have to admonish them more often.

ST11: They are sad, maybe. [..] They need more attention, and are shouting all the time, and you have to say their names all the time. They may be a little bit sad.

However, the teachers had noted individual differences between children, some either not showing their emotions or simply coping well in these less positive situations. The teachers were also of the opinion that to better understand a child who is going through a difficult phase, teachers should know something about troubling family situations. They reported often asking the parents about what was going on in cases in which a child was behaving exceptionally and neither the child, nor parents, had informed them why this might be the case. In general, the teachers reported feeling empathy, but were sometimes also obliged to guess at the possible reasons behind the emotions expressed a child.

A special feature in the Japanese teachers' data was the mention of teacher visits to families' homes during the first grade. This could mean that Japanese teachers are better aware of the child's family situation. These teachers reported that, unlike in many European countries, there is no such thing as family privacy. They perceived that in Japan, family matters are not considered as something very private and personal, but rather, professionals were entitled to know about them and to cross the family boundaries in this respect. In general, the teachers in all five countries appeared to have benevolent intentions, as they expressed concern that children in such cases may need emotional support and special attention. Of the five countries, talk about changes in the family and their links with children's emotions was the most prevalent in the teacher samples from Finland, Spain and Japan.

In Australia, in turn, it was mentioned in only one interview that a difficult family situation can manifest in children as depression and quietness. However, these attributes were attributed to the family background in general rather than to specific changes in the family. These teachers held the view that family background manifests in first-graders as either stability or instability. On the issue of family changes, the Australian teachers responses focused on the school as a community into which parents should be integrated, thereby enabling the school's parent network to offer support to individual families.

AT2: Yes, definitely, there is a community in this school and you see that when we celebrate our festivals or when we have our community market days or just even after school the parents want to stay back and let their children keep playing while they chat with each other. You know, there's a real solid network support system if a family's having a new baby, for example.
Then the parents in that class will get together and they'll cook, they'll have a roster to cook for the family. And support them that way. Or they will take each other's children to the school in their cars.

In China, the teachers reported having greater sympathy for children if they voluntarily talked about the changes occurring in the family. Otherwise, the Chinese teachers did not produce talk about family transitions in the interview. The teachers in Finland, China, Spain and Japan also stated that parents give into their children too easily and that this manifests itself at school during the first grade. These views were not expressed by the Australian teachers.

CT8: Now that most families have only one or two children, parents pay more attention to their children, they care them much more, this makes the children nowadays a bit spoiled, so that if a child falls and gets even slightly hurt, their parents will care a lot. They are not as tough as we were when we were young.

Today's first-graders' lack of ability to tolerate disappointments and frustration was a theme that was foregrounded in the interviews in Finland and Spain. According to the teachers, this also manifests itself in the classroom: some children want things right away and thus appear selfcentered to the teacher. These teachers explained that handling disappointment is trickier for today's children than for those in the past. In Australia, on the other hand, this topic was not raised at all. The Australian teachers concentrated more on the notion of the school as a community in which parents are encouraged to participate from school entry onwards. In the other four countries, community-related talk was scarce.

\section{Similarities and Differences in Teachers' Perceptions of Children's Emotions in the Five Countries}

Table 1 illustrates the similarities and differences in emphasis in the teachers' perceptions of first-graders' emotions in the five countries.

The teachers in the five countries exhibited many similarities in their views on children and their emotions. However, in no two countries were the teachers' views identical. Thus, no uniformity was observed across countries in how teachers think about children and their emotions in their respective educational settings.

If placed on a continuum, Australia, where the teachers emphasized the importance of learning emotional skills, friendliness and sociality, the connections between family and emotional skills, and the importance of community in the school transition, would be at one end. The Australian teachers rarely mentioned negative aspects of children's socio-emotional behavior during the transition to formal 
Table 1 Themes emphasized in the teachers' perceptions of children and emotions in the first grade in each of the five countries

\begin{tabular}{|c|c|c|c|c|c|}
\hline Emphases in teachers' perceptions of first-graders emotional skills & Australia & Finland & Spain & Japan & China \\
\hline \multicolumn{6}{|l|}{ Children's emotional skills } \\
\hline $\begin{array}{l}\text { Fundamental importance of children's ability to express and regulate their emotions; teach- } \\
\text { ing of emotional skills }\end{array}$ & $\mathrm{X}$ & $X$ & $\mathrm{X}$ & $\mathrm{X}$ & \\
\hline Children's problematic behavior: violence, beating, hitting others & & & & $\mathrm{X}$ & $\mathrm{X}$ \\
\hline Children's experiences of stress, worry or anxiety & & & $\mathrm{X}$ & $\mathrm{X}$ & $\mathrm{X}$ \\
\hline \multicolumn{6}{|l|}{ Emotions and transitions in the family } \\
\hline Connections of transitions in the family with emotions and reactions at school & & $\mathrm{X}$ & $\mathrm{X}$ & $\mathrm{X}$ & \\
\hline Connections of emotional skills taught in the family with emotion management at school & $\mathrm{X}$ & $X$ & $X$ & & \\
\hline School as a community supporting families during transitions & $\mathrm{X}$ & & & & \\
\hline $\begin{array}{l}\text { Children's lack of tolerance of disappointment and frustration, self-centeredness and the } \\
\text { influence of their family upbringing }\end{array}$ & & $\mathrm{X}$ & $\mathrm{X}$ & $\mathrm{X}$ & $\mathrm{X}$ \\
\hline
\end{tabular}

education. The two European countries, Finland and Spain, had the most in common in terms of the themes explored in this study. These shared themes include the importance of children's emotional skills and the teacher's role in teaching these in the first grade, and of paying attention to the possible connections between transitions in the family and children's expression of negative and positive emotions at school. Finland and Spain also shared recognition of the connections between emotional skills taught in the family and children's emotion management in the first grade, and perceptions of children's lack of tolerance of disappointment and expression of frustrations and the possible influence of their family upbringing on these. However, the Spanish teachers placed more emphasis on the stress and anxiety experienced by first-graders, a phenomenon that was hardly mentioned in the Finnish teachers' interviews.

The Japanese teachers' accounts shared most of the above-mentioned features with the Finnish and Spanish teachers. Common to both the Japanese and Spanish teachers' perspectives was a concern with children's experiences of stress, worry or anxiety during the beginning of the first school year, experiences that were mainly due to academic pressures from parents and society and long school days. However, the Japanese teachers placed more emphasis than their Finnish and Spain counterparts on academic learning and the problematic nature of children's negative behavior. China would be at the other end of the continuum, as the Chinese teachers' accounts differed in many respects from those of the teachers in the other participating countries. However, they showed some similarities with those of the Japanese teachers. While the Chinese teachers emphasized the importance of children's feelings of happiness in the first grade and their love for children, they did not discuss the teaching of emotional skills as an important component of the first-grade curriculum or the possible linkage between family upbringing and emotional skills. They expressed concern over parental demands and children's problematic behavior and uncontrollable emotions, experiences of stress and anxiety, and the inability to cope with disappointment.

According to the teachers, the teaching of emotional skills was part of the curriculum at the time of the interviews (2016-2018) in Australia and Finland, but not in Spain, Japan or China. Yet interestingly, the Spanish teachers not only considered these skills to be of the utmost importance but also stressed their dedication to teaching them to first-graders.

\section{Discussion}

In this article, we explored teachers' perceptions of firstgrade children's skills in the expression and regulation of emotions, and the role of family upbringing in the acquisition of these skills, during the transition to formal education in five countries. In addition, we investigated cross-country similarities and differences in the teachers' perceptions. In all five countries, the teachers perceived children's emotional skills in the first grade as of especial importance. Most felt a responsibility to teach children these skills, which they saw as essential for successful adaptation to school and as the foundation for all learning. The teachers reported both positive and negative emotions and behavior by children living through the transition phase. Teachers differed in how problematic they regarded these negative aspects and in how demanding or stressful the transition was for children on the socio-emotional level.

The teachers also saw the family and parents as influencing children's emotional skills during the transition to school in two distinct situations. In the first, the child's transition to school coexisted with a transition in the family. Teachers reported that children who had recently experienced the transition to the world of school simultaneously with negative or positive changes in the family, often exhibited emotional reactions such as restlessness, sadness, excitement 
or inability to perform at school. The teachers felt that they should know about such family situations in order to help the child. In fact, challenging situations in children's lives and appropriate responses to them by teachers in schools is currently a global issue. For example, Ellis (2018) identified four overarching themes on raising awareness of the unconscious processes present when teachers are working with children and families in the context of domestic violence: emotional factors related to the teacher's role, working within the school system, the teacher's relationship with the child and family, and uncertainty about what teachers need to know.

The significance of teachers in children's challenging life situations has also been noted by children: a positive relationship with a teacher can be an important source of support. Because teachers meet children on a daily basis, they may be more aware of and better able to understand children and their life worlds and more likely to recognize if a child is struggling with adverse experiences (e.g. Selvik et al. 2017; Magalhães et al. 2016; Alisic 2012). The teachers in our study reported that challenging situations in the family affect children's behavior and expression of emotions. Since children differ in their capacity to handle their emotions and in the amount of support they receive from their families, teacher support can be important for children.

The second situation brought up by some teachers concerned the impact on children of their family upbringing. These teachers reported that present-day first-graders lack skills in regulating disappointment and frustration and display marked self-centeredness. This they linked to a parental tendency to give into their children's demands too easily. However, this view was not expressed by all the teachers or in all five countries. Parenting-related anxiety is a current topic of public debate in the developed world (e.g. Sihvonen 2018). It may be that teacher perceptions that children are being spoiled reflect this debate. It is possible that situations in which teachers have to work with severely limited resources and time may amplify the importance of children's good behavior and socio-emotional skills for one's success as a teacher, as compared to situations in which teachers have the resources needed to focus on individual children and their behavior.

The diversity of teachers' views across countries was of particular interest. We explored the similarities and differences by identifying different patterns. Australia appeared to be a country in which a strong emphasis is placed on community and socio-emotional aspects of behavior. The teachers in Finland and Spain placed similar emphases on the socio-emotional aspects of behavior, the importance of knowing about family transitions, and the incidence of negative socio-emotional behavior by some children. The teachers in Japan, while sharing some characteristics with those in Finland and Spain, also placed more emphasis on academic learning and problematic behavior. China appeared to display yet another pattern, one which has less in common with the patterns of the other four countries: instead of attesting to the importance of teaching socio-emotional skills, the Chinese teachers placed more emphasis on children's problematic behavior and other socio-emotional challenges.

We interpret these findings as reflecting cross-country differences in teacher education programs, school cultures, authority relationships, resources and teachers' freedom of choice. These factors all have an impact on how teachers do their work. If teachers perceive that the primary goal of school is to teach children academic skills, this may mean neglecting children's socio-emotional skills. In general, the teachers' understanding of the importance of children's socio-emotional skills at the start of school appears to link with the emphasis in modern societies on emotion management, emotion work and socio-emotional skills in personal life and social relationships (e.g. Hochschild 1979, 2005). Emotional intelligence has become a valued quality in western societies (Ahmed 2014; Goleman 1995). The importance of emotions for children's wellbeing, particularly in the transition process, was well highlighted in the teacher interviews. Socio-emotional skills are not only valuable as such, but they also facilitate academic learning (Durlak et al. 2011). For children, early transitions are important. Hence it is essential that educators, policy makers and parents have a thorough understanding of children's experiences in educational settings in order to provide well for them (Fabian and Dunlop 2002; Pekrun et al. 2018) on the emotional level. Future research would thus benefit from addressing these questions more fully. In addition, research would profit from interrelating the themes of child emotions, social relationships, and teacher-parent collaboration, each of which is an important component, to provide a comprehensive picture of the child wellbeing during the school transition.

In previous research, it has been suggested that transition programs can be developed that include strategies to help children adjust to school (Margetts 2002). Based on our study, children's emotions, emotional skills and emotional wellbeing should be an integral component of such programs. For example, once the stresses of the new challenges for children have been identified, transition programs can be planned to minimize the adjustments required. Support in learning emotional skills and how to behave without hurting others, along with support in developing self-confidence, are examples of strategies that can be employed with children living through the transition to formal education (Margetts 2002).

Acknowledgements Open access funding provided by University of Jyväskylä (JYU). 
Funding This study was funded by Academy of Finland (Grant No. SA-21000035941).

Open Access This article is distributed under the terms of the Creative Commons Attribution 4.0 International License (http://creativeco mmons.org/licenses/by/4.0/), which permits unrestricted use, distribution, and reproduction in any medium, provided you give appropriate credit to the original author(s) and the source, provide a link to the Creative Commons license, and indicate if changes were made.

\section{References}

Ahmed, S. (2014). The cultural politics of emotion. Edinburgh: Edinburgh University Press.

Ahtola, A., Björn, P., Turunen, T., Poikonen, P.-L., Kontoniemi, M., Lerkkanen, M.-K., et al. (2015). The concordance between teachers' and parents' perceptions of school transition practices: A solid base for the future. Scandinavian Journal of Educational Research, 60(2), 168-181. https://doi.org/10.1080/00313 831.2014 .996598

Alcrudo, A., Alonso, A., Escobar, M., Hoyuelos, A., Medina, A., \& Vallejo, A. (2015). La Edu-cación Infantil de 0 a 6 años en España. Madrid: Fantasía.

Alisic, E. (2012). Teachers' perspectives on providing support to children after trauma: A qualitative study. School Psychology Quarterly, 27(1), 51-59. https://doi.org/10.1037/a0028590.

Amato, P. (2000). The consequences of divorce for adults and children. Journal of Marriage and the Family, 62, 1269-1287. https://doi. org/10.1111/j.1741-3737.2000.01269.x.

Amato, P. (2010). Research on divorce: Continuing trends and new developments. Journal of Marriage and Family, 72, 650-666. https://doi.org/10.1111/j.1741-3737.2010.00723.x.

Australian Government. (2019). School education. Retrieved from https ://www.australia.gov.au/information-and-services/education-andtraining/school-education.

Balham, N., Perry, B., \& Garpelin, A. (2016). International Perspectives on the Pedagogies of Educational Transitions. In N. Ballam, B. Perry \& A. Garpelin (eds.), Pedagogies of educational transitions: European and antipodean research. International Perspectives on Early Childhood Education and Development 16 (pp. 1-12). Cham: Springer.

Basic Education Act. (628/1998). Finland: Finlex database.

China State Council. (2010). The outline of China's national plan for medium and long-term program for education reform and development (2010-2020). Retrieved from http://www.gov.cn/ jrzg/2010-07/29/content_1667143.htm.

Corsaro, W., \& Molinari, L. (2000). Priming events and Italian children's transition from preschool to elementary school: Representations and action. Social Psychology Quarterly, 63(1), 16-33. https ://doi.org/10.2307/2695878.

Corsaro, W., \& Molinari, L. (2008). Policy and practice in Italian children's transition from preschool to elementary school. Research in Comparative and International Education, 3(3), 250-265. https ://doi.org/10.2304/rcie.2008.3.3.250.

Denham, S., Blair, K., DeMulder, E., Levitas, J., Sawyer, K., AuerbachMajor, S., et al. (2003). Preschool emotional competence: Pathway to social competence. Child Development, 74(1), 238-256. https ://doi.org/10.1111/1467-8624.00533.

Department of Education and Training. (2018). National Report. National Partnership Agreement on Universal Access to Early Childhood Education-2016 and 2017. Australian Government. Retrieved from https://docs.education.gov.au/system/files/doc/ other/2016_and_2017_national_report.pdf
Department of Foreign Affairs and Trade. (2019). The Australian Education System-Foundation Level. Australian Government. Retrieved from https://dfat.gov.au/aid/topics/investment-priorities/ education-health/education/Documents/australian-education-syste m-foundation.pdf.

Dockett, S., \& Perry, B. (2007). Transition to school: Perceptions, expectations, experiences. Kensington: UNSW Press.

Dockett, S., \& Perry, B. (2015). Transition to school: Times of opportunity, expectation, aspiration and entitlement. In J. Iorio \& W. Parnell (Eds.), Rethinking readiness in early childhood education (pp. 123-139). New York: Palgrave Macmillan.

Durlak, J., Weissberg, R., Dymnicki, A., Taylor, R., \& Schellinger, K. (2011). The impact of enhancing students' social and emotional learning: A meta-analysis of school-based universal interventions. Child Development, 82, 405-432. https://doi.org/10.111 $1 / \mathrm{j} .1467-8624.2010 .01564 . x$.

Ellis, G. (2018). Containment and denial: raising awareness of unconscious processes present when teachers are working with children and families where there is domestic abuse. Educational Psychology in Practice, 34(4), 412-429. https://doi.org/10.1080/02667 363.2018.1489221.

Fabian, H., \& Dunlop, A.-W. (2002). Introduction. In H. Fabian \& A.-W. Dunlop (Eds.), Transitions in the early years. Debating continuity and progression for children in early education (pp. 1-7). London: RoutledgeFalmer.

Fine, S., Izard, C., Mostow, A., Trentacosta, C., \& Ackerman, B. (2003). First grade emotion knowledge as a predictor of fifth grade self-reported internalizing behaviors in children from economically disadvantaged families. Development and Psychopathology, $15,331-342$.

Garðarsdóttir, B., \& Ólafsdóttir, S. M. (2017). Educators' views on transition: influence on daily practice and children's well-being in preschool. In N. Ballam, B. Perry \& A. Garpelin (eds.), Pedagogies of educational transitions: European and Antipodean Research. International Perspectives on Early Childhood Education and Development 16 (pp. 151-165). Cham: Springer.

Giddens, A. (1991). Modernity and self-identity. Self and society in the late modern age. Cambridge: Polity Press.

Goleman, D. (1995). Emotional intelligence. Why it can matter more than IQ. Lontoo: Bloomsbury.

Hacking, I. (2002). Historical ontology. Cambridge: Harvard University Press.

Hännikäinen, M. (2003). Transition to school in Finland: From early childhood and preschool education to basic education. In S. Broström \& J. Wagner (Eds.), Early childhood education in five Nordic countries Perspectives on the transition from preschool to school (pp. 77-99). Gylling: Systime Academic.

Heath, M., \& Cole, B. (2012). Strengthening classroom emotional support for children following a family member's death. School Psychology International, 33(3), 243-262. https://doi. org/10.1177/0143034311415800.

Hochschild, A. (2005). The sociology of emotions as a way of seeing. In S. Williams \& G. Bendelow (Eds.), Emotions in social life: Critical themes and contemporary issues (pp. 3-15). London \& New York: Routledge.

Iorio, J., \& Parnell, W. (Eds.). (2015). Rethinking readiness in early childhood education. New York: Palgrave Macmillan.

Irvin, J., \& Richardson, T. (2002). The importance of emotional intelligence during transition into middle school. Middle School Journal, 33(3), 55-58.

Jokinen, K., \& Kuronen, M. (2011). Research on families and family policies in Europe-Major trends. In U. Uhlendorff, M. Rupp, \& M. Euteneuer (Eds.), Wellbeing of families in future Europe. Challenges for research and policy. FAMILYPLATFORM-Families in Europe (Vol. 1, pp. 13-118). Mountain View: Creative Commons. 
Koskela, A., \& Lanas, M. (2016). Fabricating expert knowledge of the behaviour of problematic students. Pedagogy, Culture \& Society, 24(3), 459-471. https://doi.org/10.1080/14681366.2016.1196232.

Lanas, M., \& Huuki, T. (2017). Thinking beyond student resistance: A difficult assemblage in teacher education. European Journal of Teacher Education, 40(4), 436-446. https://doi. org/10.1080/02619768.2017.1349094.

Legg, C., Sherick, I., \& Wadland, W. (1974). Reaction of preschool children to the birth of a sibling. Child Psychiatry and Human Development, 5(1), 3-39. https://doi.org/10.1007/bf01441311.

Lupton, D. (1998). The emotional self. A sociocultural explanation. London: Sage.

Magalhães, M., Pontedeira, C., Guerreiro, A., \& Ribeiro, P. (2016). Integrating the prevention of gender-based violence in curriculum design and development. European Journal of Curriculum Studies, 3(2), 520-531.

Manninen, S., Huuki, T., \& Sunnari, V. (2011). 'Earn Yo' Respect!' Respect in the Status Struggle of Finnish School Boys. Men and Masculinities, 14(3), 335-357. https://doi.org/10.1177/10971 $84 \times 10369476$.

Margetts, K. (2002). Planning transition programmes. In H. Fabian \& A.-W. Dunlop (Eds.), Transitions in the early years. Debating continuity and progression for children in early education (pp. 111-122). London: RoutledgeFalmer.

May, V. (2013). Connecting self to society. Belonging in a changing world. Basingstoke: Palgrave McMillan.

McIntyre, L., Blacher, J., \& Baker, B. (2006). The transition to school: Adaptation in young children with and without intellectual disability. Journal of Intellectual Disability Research, 50, 349-361.

Miller, A., Fine, S., Kiely Gouley, K., Seifer, R., Dickstein, S., \& Shields, A. (2006). Showing and telling about emotions: Interrelations between facets of emotional competence and associations with classroom adjustment in Head Start preschoolers. Cognition and Emotion, 20(8), 1170-1192. https://doi.org/10.1080/02699 930500405691.

Ministry of Education, Culture and Sports. (2018). Sistema estatal de indicadores de la educación 2017. Instituto Nacional de Evaluación Educativa. Retrieved from http://www.mecd.gob.es/dctm/ inee/indicadores/2017/2017-seie-final-21-julio-2017.pdf?docum entId=0901e 72b8260b0e 1

Ministry of Education, Culture, Sports, Science and Technology, Japan. (2016) Overview of the Ministry of Education, Culture, Sports, Science and Technology. Retrieved from http://www.mext.go.jp/ en/about/pablication/__icsFiles/afieldfile/2017/02/15/13744 78_001.pdf.

Monkeviciené, O., Mishara, B., \& Dufour, S. (2006). Effects of the Zippy's Friends programme on children's coping abilities during the transition from kindergarten to elementary school. Early Childhood Education Journal, 34(1), 53-60. https://doi.org/10.1007/ s10643-006-0104-0.

Niesel, R., \& Griebel, W. (2005). Transition competence and resiliency in educational institutions. International Journal of Transitions in Childhood, 1, 4-11.

Notko, M., Jokinen, K., Malinen, K., Harju-Veijola, M., Kuronen, M., \& Pirskanen, H. (2013). Encountering ethics in studying challenging family relations. Families, Relationships and Societies, 2(3), 395-408.

Nurmi, J.-E., Salmela-Aro, K., \& Koivisto, P. (2002). Goal importance and related achievement beliefs and emotions during the transition from vocational school to work: Antecedents and consequences. Journal of Vocational Behavior, 60(2), 241-261. https://doi. org/10.1006/jvbe.2001.1866.

OECD. (2016). Education in China. A snapshot. Paris: OECD.

OECD. (2017). Starting strong V. Transitions from early childhood education and care to primary education. Paris: OECD. https:// doi.org/10.1787/9789264276253-en.

Pekrun, R., Muis, K., Frenzel, A., \& Goetz, T. (2018). Emotions at school. London: Routledge.

Peters, S. (2002). Teachers' perspectives of transition. In A.-W. Dunlop \& H. Fabian (Eds.), Transitions in the early years: Debating continuity and progression for children in early education (pp. 87-97). London: RoutledgeFalmer.

Pianta, R., \& Kraft-Sayre, M. (2003). Successful kindergarten transition. Baltimore: Paul H. Brookes Publishing co.

Rimm-Kaufman, S., \& Pianta, R. (2000). An ecological perspective on the transition to kindergarten: A theoretical framework to guide empirical research. Journal of Applied Developmental Psychology, 21(5), 491-511.

Selvik, S., Raaheim, A., \& Øverlien, C. (2017). Children with multiple stays at refuges for abused women and their experiences of teacher recognition. European Journal of Psychology of Education, 32, 463-481. https://doi.org/10.1007/s10212-016-0302-0.

Sihvonen, E. (2018). Parenting support policy in Finland: Responsibility and competence as key attributes of good parenting in parenting support projects. Social Policy and Society, 17(3), 443-456. https://doi.org/10.1017/s1474746417000550.

Smart, C. (2011). Close relationships and personal life. In V. May (Ed.), Sociology of personal life (pp. 35-47). Basingstoke: Palgrave McMillan.

Trommsdorff, G., \& Kornadt, H. (2003). Parent-child relations in crosscultural perspectives. In L. Kuczynski (Ed.), Handbook of dynamics in parent-child relations (pp. 271-306). London: Sage.

UNESCO. (2019). China: Education and literacy. Retrieved from http://uis.unesco.org/country/CN.

Wildenger, L., \& McIntyre, L. (2012). Investigating the relation between kindergarten preparation and child socio-behavioral school outcomes. Early Childhood Education Journal, 40(3), 169-176.

Xu, Y. (2011). Preparing young children for schools in China. In D. Laverick \& M. Jalongo (Eds.), Transitions to early care and education. International perspectives on making schools ready for young children (pp. 149-162). Dordrecht: Springer.

Publisher's Note Springer Nature remains neutral with regard to jurisdictional claims in published maps and institutional affiliations. 